The Geneva Papers on Risk and Insurance, 19 (No. 71, April 1994) 178-195

\title{
Bancassurance in Britain and France: Innovating Strategies in the Financial Services
}

\author{
by Glenn Morgan*, Andrew Sturdy**, Jean-Pierre Daniel ${ }^{* * *}$ and David Knigths****
}

\section{Introduction}

Over the last decade, in Britain, France and most of Europe the financial services industry has been characterised by the breakdown of old demarcations between deposittaking institutions such as banks and building societies and insurance providers (Salomon Bros. 1990; Thwaites 1991; Ennew et al. 1991). It is increasingly the case that those institutions with extensive retail networks are using them to sell insurance and investment products (Howcroft 1991; Stephenson and Kiely 1991; Burton 1991). This involves a major change in the nature of these institutions.

Until the 1980s, banks and building societies in the UK could rely on customers coming to them to open new accounts or to borrow money. In the 1980s, deregulation opened the way for many new entrants and weakened the ability of the existing institutions to operate quasi-cartel agreements. The expansion of lending and credit that fuelled the boom of the mid-1980s gave way in the late 1980s and early 1990s to huge burdens of unserviced debt and large losses for banks and building societies. In this context, the search for more profitable products and for more efficient use of existing resources became more urgent. Insurance and investment products (which were already being sold on a small scale in the banks and societies) became seen as one of the main areas in which new profits could be safely secured.

In France, the reasons for the convergence of the two sectors are similar. At the beginning of the 1980's, the banks became known in the "Nora-Minc Report" as the "steel industry of tomorrow" because, for a long time, they had suffered from overstaffing such as the high labour costs of branch networks. As in the UK, bank management were concerned about diversifying their services in order to improve profitability in relation to staff numbers. In addition, the 1981 banking law of "désintermédiation" effectively deprived banks of a share of their commercial business by allowing businesses direct access to the financial markets.

* Manchester Business School, University of Manchester.

** School of Management, University of Bath.

*** Centre de Recherche sur l'Epargne et les Patrimoines, Paris.

**** Manchester School of Management, UMIST.

Paper prepared for the Conference on Restructuring Financial Services, WZB, Berlin, October $21-23,1993$. 
Alongside the motivating factors to strategy experienced on both sides of the Channel, an additional factor explains the dramatic expansion of bancassurance in France. As new entrants to the insurance market and largely unconcerned about its complexities, French banks began by marketing products which were less heavily commission-based, more transparent and more flexible than those of traditional insurers. They have thus perfectly responded to the expectations of informed consumers who have, thanks to a particularly welldeveloped financial press in France, been critical of traditional life assurance contracts.

Bringing these two areas together however involves a major problem of integration. They have each developed distinctive structures, cultures and management styles over many years and the creation of one unified "bancassurance" operation is therefore highly complex. Analyzing this process as one of innovation can therefore contribute significantly to the wider problem of understanding long-term strategic change (Prettigrew and Whipp 1991: Pettigrew, Ferlie and McKee 1992: Wilson 1992).

In this paper, we address this task in a preliminary way by briefly analysing three bancassurance companies in operation from each of the two countries. The FSRC research on the changing context and strategies in the financial services industry began four years ago and has consisted of detailed case study work involving a number of companies as well as a wide involvement through formal and informal contacts with many senior executives, consultants, regulators and consumer groups in industry. This paper draws on part of that research by focusing on three particular companies which have evolved bancassurance strategies in the UK (for other relevant output see Knights and Morgan 1990; Morgan 1990; Morgan and Knights 1990: Morgan 1992).

The comparison with France has been made possible by the links between the FSRC and CREP in Paris (Centre de Recherche sur l'Epargne et les Patrimoines), a specialist and private financial services research organisation. The three case studies, typical of French companies, allow a comparison to be made between approaches in countries with different traditions: where household financial behaviour, like the traditions of the financial institutions, are quite different.

This joint article will hopefully contribute to a better analysis of what, according to many observers, will be the most important change affecting the financial services sector until the end of the century.

In the first section, we examine more deeply the underlying strategic logic behind "bancassurance" and note some of the assumptions which are built into this approach. We then consider evidence from our case studies concerning how bancassurance has been implemented in six companies - first(ly) in the UK and then France. Here we note the different routes to bancassurance and the varying problems which ermerge. We note the emergence of familiar problems of managing cultural change, creating structural forms that maximize the requisite levels of integration and differentiation and the problem of maintaining strategic vision in complex and rapidly changing environments. In the final section, we draw out some of the implications of our case studies for managing innovation and change in services.

\section{The nature of bancassurance}

There are three main categories of bancassurance in the UK.

- Where the insurance company is owned by the bank and therefore the insurance products sold in the branch network are products of the bank's own company (e.g. Lloyds, Midland, Barclays, TSB). 
- Where the bank sells the products of only one insurance company, but does not own that insurer, instead having a contractual agreement or what is called a "tied" agency with that company (e.g. Halifax Building Society with Standard Life Assurance Society, Nationwide Building Society with the Guardian Royal Exchange).

- Where the bank acts as a true broker, selling products from any, or a range of, insurers; that is, offers "independent advice" to the customer (NatWest Bank - until 1993 when it begins to use its own insurance company; Bradford and Bingley Building Society).

A fourth type of bancassurance can also be distinguished. This is the situation where a bank sells the products of a small group of insurers (normally around 4-6). In the UK, this form of tie is prohibited in the sphere of life insurance and associated investments under the Financial Services Act (a detailed account of the Act and its consequences is contained in Morgan and Knights 1990). It does, however, remain common in general insurance, where banks will maintain links with a panel of insurers whose products will be offered to customers. The TSB is the only bank with its own general insurance subsidiary though banks do brand as their own products which are underwritten by one, or in some cases, a small number of insurance companies.

In this paper, for both the UK and France, our concern is mainly with bancassurance operations which involve "backward integration" in the field of FSA-regulated products, i.e. life insurance and pensions; in other words, they involve the sale within the branch networks of the insurance products of just one company. Trends in the industry indicate that as far as life insurance and pensions are concerned "independent advice" as a whole is declining and in terms of advice within the branch networks of banks and building societies is now confined to just two major building societies (the Bradford and Bingley and the Yorkshire) since the National Westminster Bank set up its own life insurance company. Most of the major banks are now "backward integrated" i.e. own their own life insurance company. Most of the major building societies have a lower level of "backward integration", simply being tied to a particular insurer. However, there is an increasing trend for them to either buy or set up their own insurance company and complete full-scale integration. As a result between one-fifth and one-third of pre-tax profits in banks and building societies now derive from the sale of insurance products.

In France, if one considers only life assurance products, the situation at present is more straightforward than in the UK. For the most part, banks have created or bought a life assurance subsidiary which produces and manages the distributed products. It is possible to refine this analysis and measure the relative autonomy of subsidiaries in relation to their parent company. However, overall, whether measured by the number of companies or turnover, integration is very strong. For example, Crédit Lyonnais owns Assurances Fédérales; BNP owns Natiovie; Société Générale owns Sogecap, and Crédit Agricole owns Predica.

In addition to these major banks, there are several networks of medium sized banks which are legally autonomous but federated by a central body. There are examples of insurance companies working at this federal level - offering their services to regional banks who are, however, under no obligation to deal with them. The clearest example is that of Fructivie which works with the Banques Populaires. Finally, there is the particular case of an insurance company, GAN, owning a bank, Crédit Industriel et Commercial (CIC) which is in fact made up of 14 independent regional banks. 
The importance of bancassurance in the UK in the overall market for insurance can be seen in terms of the rapidity of its expansion in the life insurance sector over the past few years. In 1989, $2 \%$ of annual premium non-linked (i.e. with profit) life assurances and annuities, $7 \%$ of annual premium unit-linked life and $1 \%$ of annual premium personal pensions were sold by banks with their own insurance companies or as tied agents; in 1992, these figures had changed to $3 \%, 10 \%$ and $3 \%$ (i.e. they had increased in all sectors). Business from this type of bancassurance operation is expected to increase as the banks extend and improve their marketing and sales skills in this fee-earning sphere, and as a result of the addition in 1993 of NatWest and Abbey National to the list of banks that distribute through their own insurance companies. Building societies acting as tied agents for particular insurance companies held $5 \%$ of the annual premium non-linked assurance market and less than $0.5 \%$ of the annual premium market for linked life and pensions in 1989. These figures increased to $8 \%, 6 \%$ and less than $0.5 \%$ respectively by 1992 , indicating a considerable growth of building society activity in these areas. In the period 1989-91, the proportion of premium income coming through bancassurance outlets as a whole had increased between $75-200 \%$ for personal pensions and between $50-60 \%$ for linked assurance products.

In France, the figures are even more spectacular. In 1985, bank branch networks, including those of the Caisse Nationale de Prévoyance (the Post Office, the Public Treasury and the savings bank, Caisses d'Epargne de l'Ecureuil), collected $25 \%$ of a 75 billion Francs turnover. In 1992, this income had grown to $46 \%$ of the 243 billion Francs turnover. The distribution by banks of life assurance related products was both the condition and the consequence of dramatic development whereby the turnover increased 9 fold from 1980. With its latin and catholic culture and generous pay-as-you-go pension systems, France had, for a long time, been underdeveloped in terms of life assurance premiums per capita. It is no exaggeration to say that, through bancassurance, the French discovered a new dimension of life assurance in all its financial forms. If banks have been so successful it is because the life insurance related products they have sold were, in fact, very close to their original culture.

Prima facie, these trends would seem to support the underlying strategic view of bancassurance. In general terms, this view can be explained quite simply. A deposit taking institution normally has a branch network; before moves towards bancassurance, the network sells banking products (i.e. mainly money transmission services, savings accounts and loans). As the institution moves towards bancassurance, it begins to sell both banking and insurance products. Since the core infrastructure costs associated with running a branch network remain the same in both cases, there is an assumption that selling more products (banking products plus insurance products) will increase overall productivity and therefore overall company profitability.

However, when underlying this model there are a number of other assumptions:

- That the costs of selling insurance products are not so great as to offset potential productivity gains e.g. that the deposit taker does not have to employ so many new staff at such a high rate of salary to sell insurance products that costs rise in line with revenue and productivity gains are nil.

- That selling insurance products will not be at the direct expense of banking products e.g. customers simply switch money out of high interest accounts into bonds or insurance 
policies causing income from banking related products to fall, and meaning that overall productivity gains are non-existent.

- That trying to sell two distinctively different types of products within one framework does not create so much tension and conflict that costs of management time to control these problems and the adverse impact on overall company selling far outweigh any positive gains.

The research in the UK indicates that these assumptions are in practice very questionable. Managers find it very difficult to integrate insurance and banking at a strategic, structural and cultural level. Bankers and insurance sellers clash over fundamental values. At the risk of overstatement, we can summarise the differences as follows. Bankers are generally risk averse; they seek to develop a long-term relationship with the client; they are rewarded on the basis of seniority and qualifications (though performance related payments are gradually being brought in - often as part of the bancassurance change process). Insurance sellers are concerned to maximize their commission based earnings; turnover amongst this group is very high and there is therefore traditionally very little loyalty to the company (and little expectation of "career progression") or expectation of a long-term relationship with the client. In banking, the job of management has traditionally been primarily to deal with higher status clients. Motivation and performance of junior staff has often been loose. In insurance selling, management has played a much more active role in pressurising salespeople to achieve targets or get out. For senior management in many UK banks, bringing these two systems together is at first sight like mixing oil and water. It is a classic case where the economic and strategic logic for a certain action appears strong but the problems of implementation are likely to be immense. In the next section we examine this in more detail.

In France, if we address the same issues, it seems that the problems of implementation are less acute. The largely investment-related life assurance products considered here, which have been sold with great success by French banks are very similar in form to traditional banking products. In other words, bancassurance has not created the same human resources or cultural problems since selling the new products has not represented a radical departure from existing practices. We will see in the French case studies that follow that integration can sometimes cause management problems but not to the same extent or in the same way as in the UK cases. It is possible that in the next stage, when French bancassurers begin to market ordinary life assurance and, in particular, general insurance that a certain number of the problems experienced in the UK will emerge.

\section{Bancassurance in implementation}

\subsection{The UK}

The ideal of bancassurers is to utilize customer information and contact in order to sell new insurance and investment products either within the branches themselves or outside. In the main, the UK institutions have recognised the difference between insurance selling and banking. They believe that selling insurance products is not a skill that can be simply tackled on to the other skills that are used in retail financial services. Instead, they believe that it requires certain special skills which need to be nurtured by an appropriate management and incentive scheme. However, too large a gulf between a specialist salesforce and the deposit institutions's normal staff would undermine the potential advantages from bringing the two together. Thus it is characteristic of attempts to integrate insurance selling and the branches 
of deposit takers that there is a system which ensures that potential sales opportunities are identified by a non-sales specialist (e.g. a teller or a person on an enquiry desk). This process of identification then allows the "prospect" to be approached by the specialist seller either directly in the branch or at home. The key question for the management in these contexts is how to make sure this triangular set of relationships - customer: branch employee: specialist seller-works successfully. This requires creating structures, cultures, management controls and incentive systems that produce cooperation and cohesion rather than conflict and disorganization. In the case studies which follow different ways of managing these relationships are examined.

\section{Case 1: ShilCo 1}

ShilCo is a major UK financial services retailer. It possesses a nationwide branch network and owns an insurance company (ShilInCo). ShilInCo products are sold almost entirely to ShilCo customers. ShilCo branch staff are divided into ordinary cashiers and customer service representatives (CSRs). Any enquiries about insurance or investment products are referred to CSRs who establish in general terms the sorts of product which the customer needs. If these relate to general insurance products or mortgages, the CSR will conduct a full interview and, if possible, make the sale. If the customer's needs are related to FSA-regulated products, then the customer will be referred on to a representative of the insurance company ShilInCo. The representative of ShilInCo will actually have a small office space in the branch and will have a diary kept which will indicate when he/she will be in the branch. The ShilInCo representative will discuss the client's needs in the branch and may make a sale. More likely, however, is that an appointment will be made at the client's house and the sale will be made there. Other leads will be generated by the bank manager writing direct to clients with advice about the insurance and investment facilities offered by the company and either inviting them into the branch to see the ShilInCo representative or informing them that the ShillnCo representative will be visiting them at their home at a specified time.

All the ShilCo staff are paid on a normal salary structure, with only a small commission element. Branches are targeted in a number of ways, including the amount of insurance premium income that is generated. Individual branch employees are also targeted in terms of the number of leads they are expected to generate for the ShilInCo sales representative. Career progression and favourable appraisal reports will be in part determined by the individual employee's ability to demonstrate a good working relationship with the ShillnCo person. The ShillnCo employee is paid by commission only. Although employed by ShilInCo and provided with a car and various other benefits such as private health care, non-contributory pension and subsidised mortgage, salary is determined by the number, size and quality of sales made. As an employee of ShillnCo, the salesperson will be responsible to the ShilInCo management even though he/she will be working inside the branch alongside branch employees. The salesperson will be set targets for business by ShillnCo management on the basis of company targets and previous individual performance. Sales management apply strong pressure on the salesperson to meet targets.

The ShilInCo model is based on management's strong belief that insurance and investment selling involves different skills to normal money transmissions and lending products

${ }^{1}$ For reasons of commercial confidentiality, the companies involved in the research were promised anonymity in any subsequent publications. 
allied to a determination to utilize the "warm" lead generated in the branch to initiate the sales process. It is therefore not only committed to a dedicated salesforce and a specialist management system with different remuneration structures and target mechanisms from those appropriate to branch staff but also to these two groups working in the same physical location.

ShilCo is often quoted as a good example of how bancassurance can work in the UK. It is seen as one of the innovators in this field and it has certainly a great deal of experience, having first begun in the 1970s. Yet ShilCo has been working at this model for nearly twenty years and has still not come up with a final version. Behind the image, there have been a number of clashes amongst top management which have resulted over recent years in a number of reshuffles and resignation. These arise basically from the fact that there is a cultural clash between insurance and deposit-taking which is magnified by the actual physical proximity within a single branch of representatives of these distinct values. Branch staff at all levels have at various times resented the insurance sellers for a number of reasons, including their high earnings and their instrumental and at times high-handed attitude towards branch staff and customers. Furthermore, there was a perception within the ShilCo senior management that at a time when they were under intense pressure to cut costs both in branches and head-office, the insurance company was still spending on ostentatious new buildings and presenting itself as highly profitable (since it was, in accounting terms, getting the use of the branch facilities for nothing). These difficulties (together with changing market conditions) led at one period to a significant decline in productivity as in certain branches, individual bank employees (at both management and clerical levels) informally withdrew cooperation with individual ShilInCo representatives, thus making it far more difficult to generate "warm leads". At one point, it appeared possible that the two might become separate with ShillnCo seeking to cultivate a customer base distinct from that of the branch network and ShilCo employees selling the products of other insurers (though the regulatory system made that difficult). This reflected a process of drift at ShilCo's head office where senior management brought up in a less turbulent and changeable environment were finding it hard to cope with all the changes of the late 1980s. For a time, strategic vision had deserted the company and conflicts at lower level were allowed to develop.

Eventually, with the advent of new top management the senior management of the two companies reached an agreement about how leads were to be handled and how the two groups of employees would be managed. This agreement stabilized the situation whilst ShilCo senior management set about bringing the insurance company under more direct control. ShilInCo underwent a series of major reorganizations during which many of the original senior management of the company left and were replaced by newcomers. These senior management had been with the company from the start and had built up a very close relationship with other employees, particularly the salesforce. Their removal led to a severe crisis of morale which was exacerbated by the downgrading of ShillnCo's independence by the gradual stripping out of its strategic planning and marketing functions from its head office. These were removed to the head office of ShilCo and integrated more closely with the overall planning system. These reorganizations removed any pretentions that ShilInCo might have had that it could go alone. These served as both real and symbolic markers for the ShilInCo sales staff that they had to learn how to get on with branch staff. This in turn was reinforced by new forms of team-building, targeting and monitoring that emphasized a positive relationship between the two groups of employees at branch level. Thus ShilCo 
is now much more clearly the more powerful entity with the insurer serving the needs of the branch network as defined by the ShilCo senior management. ShilCo is continuing to integrate branch and insurance staff both at head office (where there is now a single division of deposit-taking and insurance) and at branch level.

\section{Case 2: BulCo}

BulCo is a major retail financial services institution with a nationwide branch network. BulCo started on bancassurance later than ShilCo. Although it owned its own insurance company, this was for a number of years kept at arms-length from its banking operation. Even when the Financial Services Act forced an overt declaration of tie between the two, the link was not strongly developed. BulCo management were concerned about the adverse impact of the insurances sales process on their banking operations. Only when senior BulCo management began to develop a more clearly focussed strategy which necessitated higher profitability and productivity from their branch network did bancassurance properly develop. Furthermore this was achieved through linking up with an existing life insurance company with a direct sales force to form a new insurance company (BulInCo which integrated parts of BulCo's previous insurance company with parts of its new ally's operations). This link was supposed to give BulCo direct access to the selling skills for which their partners were renowned.

BulCo management recognised that bringing together these two areas, banking and insurance, needed special attention. Rather than simply bring a direct sales force into its branch network, it opted for a more complex division of labour BulInCo products are sold to BulCo's customer base (i.e. its bank branch customers) through its branch network; however, BulInCo attempts to keep its specialist insurance salesforce outside the branch environment. As with ShilCo, the initial contact is expected to be with cashier staff. These staff seek to screen out customers with the potential to buy investment and insurance products. Unlike ShilCo, however, in BulCo, customers can be referred either to specialist sellers within the branch (who are employed by BulCo) or to specialist sellers outside the branch (who are employed the BulInCo).

Within the branch, there is an in-house salesforce as well as a number of advisers who travel locally between branches. These specialist sellers within the branch will deal with loans and general insurance as well as certain FSA-regulated products. They receive a standard salary with a marginal commission element. In career terms, they learn selling as one of the elements of modern retail financial services practice and although they specialise, they may still find themselves doing routine cashiering tasks if necessary. The out of branch salesforce is run by BulInCo. Unlike ShilInCo representatives, there is a basic salary but this is only small and commission earnings are expected to predominate. Recruitment, training and coaching is undertaken by specialist sales managers. A further distinction from ShilInCo reps is that BulInCo reps, although allocated to branches, are not expected to physically locate themselves there and wait for lead referrals and sales opportunities. Instead, the branch manager and the staff will seek to make appointments for the representative at the potential client's home. In theory, the representative may come into the branch to meet the manager and the staff but only to develop a friendly relationship, not to directly meet clients, though there is a temptation for them to spend time in the branch meeting customers as well as staff. 
BulCo then have two potential sales channels - one is that of the specialist insurance company salesforce, the other is that of their own specialists within their branch. Branches are set targets for business under the various categories of product and managers have a certain autonomy as to distribute potential leads within the two salesforce categories. In general terms, it is expected that more complex products such as pensions and bonds will be sold by BullnCo representatives, whilst more straightforward life insurance and investment products are sold in the branch. However, branch managers have a certain autonomy about how to manage this balance so long as they are achieving their overall targets.

In the case of BulCo, the branch environment is "uncontaminated" by any outside influence. BulInCo still draw on branch leads but they work predominantly outside the branch. The interface between BulCo and BulInCo occurs through the lead generation process which can be via telephones and letters rather than as a direct face-to-face interaction. This is monitored within a matrix management system whereby the cross-cutting responsibilities of BulCo and BulInCo management are the subject of "gate-keeping" by specially designated head office and regional management in both companies whose role is to liaise and anticipate any problems or deal with them as they arise.

Problems in BulCo do not arise from the direct confrontation of different cultures as in the case in ShilCo. Instead, the problems for BulCo revolve around its customer base. The organization is increasingly sales driven; employees in the branches as well as in the insurance salesforce are targeted to sell. Every person the customer comes into contact with will be trying to sell. Customers may come to resent this and purposely avoid the branch. From the employee's point of view, the pressure to sell means that there may be resistance to passing on leads. Until one's own targets have been met, why pass prospects to somebody else, even if that other person may be more experienced and skilled? BulCo's problems are to make sure that its customers are not experiencing over-selling but are on the other hand meeting with the appropriate type of salesperson from the range of possible sellers. As yet there still appears to be competition between the different sales channels and a degree of uncertainty amongst management as to how to manage this. On the one hand, this competition can be seen as a positive feature, contributing to the creation of a strongly sales-driven culture. On the other hand, it may be dragging down overall productivity because customers are not getting in front of the right type of salesperson for their particular needs. It may also be storing trouble up for the future in that customer resistance to over-selling may begin to grow. Senior management in BulCo are therefore seeking to develop a model of the selling process that will allow for a greater degree of discrimination between types of customers and the appropriate sales approach. In taking a more complex approach than ShilCo, BulCo appears to have avoided the worst of the clashes that have inhibited progress inside ShilCo; however, they have not yet been able to match the complexity of their conception with a working operational model.

Case 3: ColCo

ColCo operates a third distinctive model. It is a medium sized provider of retail financial services with a strong regional base; it owns an insurance company (CollnCo) whose products it sells through its branch network. In the past, ColInCo products have been sold by branch staff who have been given special training. This staff receive leads from cashiers and then try to sell insurance based products to branch customers. In career terms, they are part of the normal grading structure within ColCo and receive no commission for their sales. Working in the selling function is seen as necessary to proceed up the hierarchy of 
ColCo. In materials terms, however, there is no immediate incentive for an individual staff member to take on the task. Sales are primarily conducted in the branch and there is little home visiting. The time, skills and incentives required to sell the more complex pension and investment products are not therefore provided.

ColCo's management feel that as a result they are not utilizing their bancassurance possibilities to the full. They have therefore decided to set up a specialist sales force to sell insurance products to their customer base. This salesforce will receive leads from the branch staff which it will follow up through home visits. It will be physically located outside the branch network and will not therefore come into direct contact with the branch staff. It will be paid a basic salary (higher than BulInCo) with commission on top. Unlike BulInCo and ShilCo, however, the specialist salesforce will not be employed by the insurance company. On the contrary, they will be managed and controlled by ColCo. Although ColCo recognise that they will have to bring in specialist salesforce management skills, they nevertheless wish to keep ultimate control by integrating the salesforce within ColCo itself. Thus the insurance company remains effectively a manufacturer (of insurance products), whilst ColCo is the distributor and seller of the products.

The issues for ColCo revolve around two problems. First, does it produce sufficient business to make a specialist salesforce worthwhile? A specialist salesforce paid by salaries and commissions is an expensive proposition; will it bring in enough new business to be a worthwhile investment? Secondly, can it be managed in such a way that it does not create a disruptive effect on the already existing branch selling system? ColCo employees have grown used to selling within the branch; now they will have to get used to passing leads on to sales people they do not know. ColCo prides itself on the local knowledge of its branch staff and their care for customers as individuals. Under the new scheme, customers will be referred to salespeople with whom the branch staff may have only a passing acquaintance, yet whose actions may considerably affect customers' perceptions of ColCo as a whole. ColCo managers face a dilemma. If they want salesforce to be economically viable, they will have to grow it quickly and achieve high targets; if they do this, however, they risk generating dissatisfication amongst their branch employees. ColCo hope that by keeping the management of this process in the hands of one group of senior executives they can avoid the sort of intra-managerial conflicts which characterized ShilCo. Whilst this may be true, it is not yet clear that they can avoid a fall in morale amongst their branch employees.

\subsection{France}

We have seen that in France the reasons for the convergence of banking and insurance are of a similar nature to those in the UK. However, in presenting these 3 French case studies, it is important to note that bancassurance in France is a relatively new and sudden phenomenon. Certainly, the development of bancassurance in the UK has accelerated in recent years, but banks and building societies have sold both life and general insurance at modest levels for decades to what was, to them, a mature market. In France, with the notable exception of the Crédit Mutuel Bank, bancassurance began in the 1980's and represented both the condition and consequence of an explosion in the turnover of life assurance. For a number of traditional insurance companies, this explosion was experienced as an aggressive conquest of markets which they had previously considered as their own. Bancassurance was not simply another marketing approach to personal customers, it was a subject of controversy. 


\section{UMINCO}

The banking-insurance link began in this group 20 years ago when UMCO, an important deposit bank, bought a small life assurance company which distributed through "agents généraux"*. This acquisition was initially an industrial investment but after only 5 years, UMCO began to use its subsidiary to produce unit trusts and, subsequently, "capitalisation" bonds, both very similar to traditional banking products. The "capitalisation" bonds were sold through the bank branch network which marked the beginning of its bancassurance development.

It was the beginning of the 1980's which marked the start of the boom in life assurance and which coincided with economists' publications which highlighted the problem of overstaffing in French banks. This macro-economic context is important: it accounts for the two key ideas informing the development of bancassurance at UMCO. Firstly, it was a question of making the Branch network more profitable, the impact of which was recognised by its competitors, and, at the same time developing customer loyalty. Indeed, the appearance of the new generation of life assurance products coincided for UMCO, who had a relatively high net-worth/upmarket customer base, with a large loss of deposits. Its customers had switched their investments to competitor companies and had already begun the move towards more flexible and transparent contracts.

These two factors explain why in the branches now, all the staff are able to offer insurance products which are totally integrated within the whole product range. All the sales staff have received training in life assurance and some, specialist training which is more comprehensive than that which is legally required, in order to sell insurance to the public. These specialists have to manage and support the counter staff, and everybody who, in the bank is in relation with the customers, must be able to provide basic information about insurance.

Given that life assurance products are integrated into the range of banking products, it is logical that the form of staff remuneration is the same. The approach of UMCO is that remuneration must be neutral in relation to the product and, except during a launch period, no special remuneration is linked to the sale of either banking or insurance products.

The logic of full integration of UMINCO's products is always incorporated into UMCO's frequent promotional campaigns which focus on particular product types. Such campaigns are common in all French banks, reflecting a strong market push. UMCO has a distinct competitive advantage in relation to other companies in the skill with which its subsidiary's life assurance products are integrated into the promotion and sale of the complete product range at branches. The integration reflects the recognition of its importance by the top management at UMCO and lies behind the commercial success of UMINCO.

Establishing this successful combination of banking and insurance products and the apparently harmonious relations between the two companies was not without its problems. During the first years of collaboration, when UMINCO, which had kept its original name, began distributing its products through the bank branch network, there was considerable misunderstanding between the insurance company staff and the bank management. The recruitment of a number of the bank marketing staff to the insurance company ended in failure and the bank's I. T. systems were found to be unsuitable for processing insurance business. Finally and most importantly, the senior management at UMINCO at the time had

\footnotetext{
${ }^{*}$ Tied agents selling mainly non life insurance.
} 
absolutely no understanding of the bank as a client. It had failed to recognise the idea that the subsidiary must supply its parent/client with those products which it wanted to sell.

The conflict was permanent - the insurers not only thinking that the bankers were not understanding their business but also hardly making any effort to explain it to them.

The arrival of new senior management at UMINCO - Chairman and Chief Executive - led to a normalisation of relations. The different parts of the bank became conscious of the technical difficulties of a new business discipline and the new UMINCO team created a new climate of confidence which made cooperation possible and saw integration as necessary. These changes coincided with a change in the insurance company name to one linked with that of its parent. Gradually the original management team was ousted and the arrival of new Chairman and Deputy Managing Director marked the end of this particular phase.

The importance of mutual understanding and confidence between the bank and its subsidiary is, without doubt, the principal lesson to be learned from the experience of UMIN$\mathrm{CO}$. The obstacle which resistance to change can represent such as that of UMINCO's senior management, is illustrated by these years of conflict and opposition. These could only ever have been a "rearguard action" doomed to failure since UMCO owned the capital and controlled the distribution network. It was only through seeking mutual understanding that UMINCO could recognise its distinctiveness. By cooperating without reservations with the parent company it was able to maintain a measure of autonomy. This is necessary in order to offer products to customers in the branches which they have the right to expect from their bank's insurer and to offer products which conform to the insurance regulations. It seems that, today, UMINCO have succeeded in this regard.

\section{LILINCO}

The situation at LILINCO is particularly complex in two respects. Firstly, in terms of distribution, the company sells its products through the LILCO branch network which is made up of a large number of regional and legally independent banks brought together by a central body. The influence of this organisation varies for each bank according to their size and historical or personal links. When LILINCO was formed, the extent of insurance activity between banks varied: some not seeing the value of these new services and others, by contrast, already working as distributors of traditional insurance companies' products. However, today, the situation is standardised and all the constituent banks of LILCO only sell LILINCO products.

The other source of complexity of LILINCO relates to the management of its insurance contracts. LILINCO uses the administrative and technical services of another insurance company which sells its own products under its own name or distributes them through networks other than that of LILCO. Moreover, the capital of LILINCO is held equally by the insurer and the network of LILCO banks.

The products sold are deliberately kept simple - in keeping with the banking culture. Most frequently they are single premium products to match as much as possible the existing practices of bank sales staff. LILCO's client base is predominantly made up of low to medium income groups and neither the counter staff nor the customers are prepared to deal with very sophisticated products. This belief shared by the senior management of both the bank and the insurance company explains how insurance is sold by all those staff who have contact with customers, whatever their level of competence. 
At LILCO, there is no specialisation of sales staff according to product type and if the client needs are simple then the sale of insurance products can be carried out wholly by the bank counter staff. On the other hand, if the initial needs analysis suggests a requirement for a more complex product, then the prospect will be referred to a more experienced, yet still generalist, seller. The only mode of differentiation produced by some of LILCO's banks is based on clients' level of income and overall financial wealth (patrimoine). Beyond the counter staff, certain sales staff are allocated to "middle of the range" customers and others to the relatively "well-off". This distinction between staff, associated with the bank's marketing policy becoming more targeted, has generated tensions within the sales network. Some salesman seem to be advantaged by the fact that the bank's commercial policy may, during a particular period of time, be more dedicated to the customer segment for which they are responsible.

The identification of LILINCO's products with the image of the bank is total with the insurance company management readily confirming that their clients are the LILCO banks and not the insureds. The rapid commercial success of LILINCO, coming into bancassurance more recently than in other French banks, confirms the value of this orientation. However, two current difficulties illustrate the problem of resistance to change - a recurrent theme in this paper.

The bank staff have had difficulty in selling term insurance products despite the fact that these contracts meet the regular needs of their customers. The staff at some of LILCO's banks are not highly motivated and are reluctant to move from a culture where they simply collect deposits (this is the case for banking products but also investment related life assurance) to one where the bank receives a simple commission. In addition, there is a difficulty with sales staff misunderstanding the requirement for medical details to be obtained and who sometimes combine the risk and management costs elements of a premium without understanding the principles involved.

The other difficulty for LILINCO is associated not with distribution network but with the insurance company which manages its contracts. This sub-contracting had obviously been a great advantage when LILINCO first began operating in that no substantial investment was required in administration systems. However, today it has become inconvenient in that there is insufficient administrative flexibility to serve several clients and either the incapacity or an absence of will to adapt services to each client's requirements. For LILIN$\mathrm{CO}$, the situation is especially difficult since if the insurance company is not only a sub-contractor but owns $50 \%$ of its capital, it cannot behave with a principal shareholder in the same way as it would with a simple supplier.

Beyond the political problems between administration and marketing orientations, which are, after all common in many organisations, this dual shareholding presents a more serious problem - that of sharing the added value of insurance activities. With the capital split equally, LILINCO finds itself in a very uncomfortable situation. The insurance management company sees its service as being inadequately remunerated while the distributorthe banks - regards its sales commissions as insufficient. At the same time, both contribute to LILINCO's profitability. The political stakes are high, particularly because the spectacular success of LILINCO throughout recent years can only heighten the covetousness of both the interested parties. The future, as is almost always the case in this type of conflict, will be that the mode of distribution (i.e. the bank) will prevail over the administrators and result in a challenge to the current parity in the shareholding of LILINCO. 


\section{VILCO}

VILINCO is another subsidiary of one of the large structures of autonomous regional banks which are specific to the French banking system. The grouping of VILCO companies constitute one of the largest players in the personal banking market. Entering into bancassurance a little later than some of its competitors, VILINCO has experienced rapid growth, with exceptional increases in turnover placing the group amongst the market leaders.

The primary characteristics of VILINCO is its complete integration with the marketing policy of the parent company with regard to both product development and distribution. Given the buoyant nature of the market, VILCO's creation of a life assurance company was clearly necessary. However, from the start, its products were totally integrated within the product development policy. This was outlined by the central management at VILCO and its constituent legally independent regional banks. Life assurance was seen as a means of bringing a supplementary service to VILCO's clients, not simply as an isolated product. This contract must be part of a range of products; it is there to complete the range and may even contribute to the evolution of the whole range, but always bearing in mind that the primary reference point remains the range of services offered by the bank to its customers.

The integration of insurance occurs logically at the point of its distribution where it has been made a standard product alongside the other services offered in the network. This network has the reputation of being commercially active and its impact comes at least partly from the regular practice it has of going to visit customers at their place. Even if this occurs less frequently because of the time it takes and even though it does not wholly conform to a global approach to client needs, the sale orientated dimension remains at the heart of the network and has contributed to the dramatic success of VILINCO.

In the VILCO branches, the management objective is that all these staff who are likely to have customer contact are able to talk to clients about simple insurance products in the same way as they can with basic banking products. Moreover, from the beginning, VILINCO sold insurance products which were very similar to banking products in order to minimise the cultural shock which could have happened with the introduction of more technical insurance products. In the massive training programme carried out by VILCO's training department, the concern was to respect the existing orientations and practices of the staff.

Each of the banks making up VILCO have some autonomy in relation to the remuneration of their staff, particularly the sales staff. Consequently, the way in which selling VILINCO products is rewarded can vary between banks but within each one the system of motivating sales staff is the same regardless of the product type. Each bank outlines its sales objectives, including those for insurance, and these are communicated to the sales points. Insurance is always integrated - treated on an equal footing with the other products sold by counter staff. This method of remuneration conforms to a global approach to client needs which is a primary and explicit objective of VILCO's strategy. In other words, for the seller to give objective advice to the client in terms of choosing from the available product range the product most suited to his/her needs, differential remuneration by product type should not be practised.

In almost all the sales points, there is an employee who has the legal authorisation to sell insurance. $\mathrm{He} / \mathrm{she}$ is responsible for distributing among the salesman the insurance sales objectives of the branch in which he is located. These objectives have been jointly 
set by management of the regional bank management VILCO and VILINCO. Once again, given that the method of remuneration does not reward one product more than another, it seems that throughout the structure, including within the sales force, relations are harmonious in this regard.

Integration is then a dominant feature of VILINCO's strategy. While this may have always been the case amongst the rank and file and therefore within the bank branch network, it was not always evident at the most senior levels of hierarchy. Several years after VILINCO formation and at least partly because of its dramatic success, relations between the parent and subsidiary became acutely strained. In accordance with its global strategy as an integrated financial group seeking to achieve a balanced policy in raising funds from its personal customers, VILCO decided to promote products which could fit directly into its balance sheet. Accordingly, the bank decided to contain the growth of its insurance subsidiary. This act immediately expressed itself in a sharp fall in insurance turnover, after what had been steady and dramatic growth. In effect, the VILCO network almost exclusively sold "pure" banking products as effectively as it had sold insurance products in the previous year.

The containment of insurance business was not very well received by those senior managers at VILINCO who did not originate from the upper echelons of the bank. Coming after a growth which had stunned competitors and brought VILINCO inexorably to the top rank of market players, the interruption in business was not understood by those who did not share the culture of the VILCO group. Their opposition to the policy was intensified by the fact that parent company had no sense of its oppression of the subsidiary. In the logic of group finance, life assurance was simply one of a number of ways to collect savings. Putting the emphasis on a particular form of savings in a given year can be seen as perfectly normal and no cause for a subsidiary to develop its own culture and spirit. It is always possible to relaunch insurance products as and when required by the parent company. This policy of rapid expansion followed by withdrawal is nothing shocking. It is only the expression of the direction of the central banking group.

Two incompatible rationalities confronted each other and it is clear that in this struggle the parent company prevailed. The chief executive of VILINCO resigned and was replaced by a director from VILCO who had, in his career with the bank, developed good relations with the managers of the local banks. His first task was to bring an understanding to the insurance subsidiary of the necessity to integrate with the objectives of the bank. During its first years of existence, the insurance company had recruited employees from outside the VILCO group who had seen their company as dynamic and successful, not as the strategic instrument of a parent company. It was necessary to transmit to this group a feeling of being part of the organisation. This had developed elsewhere, in that other VILCO employees had worked and developed their careers in subsidiaries but almost always with the continued support of the parent company and its strategy behind them.

This crisis period is now over but it was accompanied by a change in the top management which, except in the case of the chief executive, was carried out gradually. More than previously, the current directors are originally from VILCO. Given their familiarity with the ways of the parent company, they have developed close working relationships with the management both at the head office and the regional banks. 
As in the case of UMINCO, we can see the importance of mutual confidence between the parent and subsidiary companies. For the current directors of VILINCO, the lesson to draw from the past is the necessity of working together with regional and national management levels. It is probably because of the inadequate nature of this dialogue in the early years that the change in policy degenerated into a crisis. In terms of our analysis of the management of change, the "culture-gap" in this case is not that between banking and insurance, but between different levels of a group organisational structure. More specifically, it is between the directors of a strongly integrated structure with a group spirit and those of a subsidiary which wants to assert its identity at the risk of challenging the overall objectives of its parent which is, within the framework of bancassurance, not only the shareholder, but also the distributor.

\section{Conclusions: Implications for the management of change and innovation}

In general terms, it is possible to distinguish two sorts of problems that are at issue here in trying to create the innovations characteristic of bancassurance. Firstly there are a range of operational problems that come primarily from trying to make the link between deposit taking and insurance selling. They concern how to manage the lead generation process, how to ensure customers receive consistency of service, how to create a system whereby customer needs are properly addressed in order that they can be served by the appropriate person. In theory, these operational problems are going to be most susceptible to resolution where insurance selling and the deposit taking functions are most integrated. In other words where all the sellers and tellers are controlled by the same management, receive the same core training and socialization into the company's mission statement, salary and career differentials are minimized, formal and informal contacts between the groups are maximized.

In this respect, it is interesting to compare the situation in France and in the UK. It seems that the problem of resistance to change has been more easily overcome in France because, for the most part, banks' insurance subsidiaries have sought to minimise the change. It is striking to note how they have all recognised the necessity of adapting themselves to the bank's culture, of integrating the bank's product range and of adopting the bank's sales remuneration and reward system. It is no exaggeration to say that bancassurance has succeeded better in France when the insurers working with banks have erased their specific sales methods and product combinations to ease the cultural shocks which have been so marked in the UK.

In the UK, achieving this sort of integration requires a protracted transformation in the culture and structure of financial services organizations to overcome the differences that currently exist. Thus they are linked to problems in the management of change. These can be summarised under in terms of changing a deposit-taking culture towards a more selling orientation, creating a salary and career structure which provides security of employment but within a framework which encourages motivation and performance, creating relationships within a branch environment that reorder status hierarchies and enable a team approach to the selling process.

However, banks and building societies have a considerable inbuilt resistance to change and innovation. Only in the last decade have they begun to be forced to look outward and develop new strategies which demand that they actively compete for new business and customers. Perhaps the largest innovation which they have attempted has been to turn themselves into "bancassurance" operations and their branch networks into "financial super- 
markets" which offer a wide range of services. This innovation has had massive implications for the structure and culture of the organization as well as for the careers of the people who work in these organizations.

In the six cases under review, reflecting different corporate as well as national cultures, different ways of managing the process of transformation are being used. A definitive verdict of which is the "best way" cannot be delivered, due both to the complexity of measuring "best" and to the problem of deciding the appropriate time-frame in which to make such a judgement. What is true today may not be true tomorrow.

However, recognising these qualifications, we feel there are certain lessons which can be drawn from the case study examples. In our view, those organizations which recognise that bancassurance is part of a long term process of change will be most successful. In addition, one could conclude from the French examples that a certain caution or modesty in the initial launching stage may help to ensure success inasmuch as this reflects a long term perspective of change. In this perspective, a strategic vision of how banking and insurance fits together needs to be translated into a structure which emphasizes operational integration of the two aspects rather than differentiation. This does not mean that the two lose their distinctive identities but rather that at the point where they meet face-to-face, similarities rather than differences are emphasized.

Major strategic change and innovation such as that being attempted in the move towards bancassurance is a highly complex process. There is no one best way to achieve it; it involves strategic vision and effective management of structural and cultural change. In environments as dynamic and changeable as that of the financial services over the last decade, these skills are stretched to their limit. The structures of organisations, like the people who work within them, have been under great pressure while the financial services sector had, until now at least, remained relatively protected. The conditions leading to bancassurance as a business strategy followed and reinforced the revolution in management associated with information technology. In both cases, financial services organisations followed those of industrial sectors. It is hoped that the joint efforts of academics and practitioners contribute to a better analysis of these changes. It is a question of discovering in the present conditions the principles of change management which will be applicable in the future to other sectors affected by changes of the same scale. 


\section{REFERENCES}

BURTON, D. (1991) "Tellers into Sellers?" International Journal of Bank Marketing, Vol. 9, No. 6, pp. $25-29$.

DANIEL, J.P. (1992) La Bancassurance - Fin de la première étape ou dernière étape avant la fin? 224 p. Les Editions de Verneuil, Paris.

ENNEW, C., WATKINS, T, and WRIGHT, M. (1990) "The New Competition in Financial Services" Long Range Planning, Vol. 23, No. 6, pp. 80-90.

HOWCROFT, B. (1991) "Increased Marketing Orientation: UK Bank Branch Networks", International Journal of Bank Marketing, Vol. 9, No. 4, pp. 3-9.

KNIGHTS, D. and MORGAN, G. (1990) "Management Control in Sales Forces : A Case Study from the Labour Process of Life Insurance” Work, Employment and Society, Vol 4, No. 3, pp. 369-389.

MORGAN, G. (1990) "The Management of Sales Forces” Personnel Review, Vol. 19, No. 3.

MORGAN, G. (1992) Strategic Issues in Personal Financial Services, London: Datamonitor.

MORGAN, G. and KNIGHTS, D. (1990) The Financial Services Act: The Origins, Causes and Consequences of a Regulatory Regime, Research Report : Financial Services Research Centre, Manchester School of Management, UMIST.

MORGAN G. and KNIGHTS, D. (1991) "Gendering Jobs: Corporate Strategy, Managerial Control and the Dynamics of Job Segregation” Work, Employment and Society, Vol. 5, No. 2, pp. 181-200.

PETTIGREW, A. and WHIPP, R. (1991) Managing Change for Competitive Success, Oxford: Blackwell.

PETTIGREW, A., FERLIE, E. and McKEE, L. (1992) Shaping Strategic Change, London : Sage.

SALOMON Bros. (1990) Multinational Money Center Banking: The Evolution of a Single European Banking Market, London : Salomon Bros.

STEPHENSON, B. and KIELY, J. (1991) "Success in Selling - The Current Challenge in Banking", International Journal of Bank Marketing, Vol 9, No. 2, pp. 30-38.

THWAITES, D. (1991) "Forces at Work: The Market for Personal Financial Services" International Journal of Bank Marketing, Vol. 9, No. 6, pp. 30-35.

WILSON, D. (1992) A Strategy of Change, London: Routledge. 